\title{
EDITORIAL
}

\section{Is nosocomial infection really the major cause of death in sepsis?}

\author{
Neil M Goldenberg ${ }^{1}$, Aleksandra Leligdowicz ${ }^{2}$, Arthur S Slutsky ${ }^{2,3,4}$, Jan O Friedrich ${ }^{2,3}$ and Warren L Lee L, $^{2 *}$
}

\section{Introduction}

Over 25 clinical trials for sepsis have failed [1,2], suggesting that our current understanding of its pathogenesis is incomplete. Deaths occur days to weeks after diagnosis and have been attributed to one of two phenomena [3]. First, a subset of patients succumbs to an overwhelming acute inflammatory response driven by the innate immune system, leading to death within days of the initial infection. However, most patients survive this phase and the repeated failure of anti-inflammatory therapies for sepsis (for example, anti-tumor necrosis factor antibodies [4], high-dose corticosteroids [5]) indicates that inflammation per se is unlikely to be a major cause of death. Most sepsis deaths occur later and have been associated with dysfunction of the innate and adaptive immune systems [6], characterized by decreased cytokine production and lymphocyte apoptosis [7]. These mechanisms have been postulated to cause immunosuppression $[3,8,9]$, predisposing patients to fatal nosocomial infections. Based on this hypothesis, immunoadjuvant therapy to boost the immune system has been proposed recently as a therapeutic approach.

\section{The argument against nosocomial infection}

The notion of death due to nosocomial infection is at odds with our clinical experience, in which patients with sepsis die despite broad-spectrum antibiotics and negative microbial cultures. Indeed, two studies often cited as evidence for this theory are open to alternative interpretations. The first study reported a high $(\sim 80 \%)$ rate of infected foci in those patients dying from sepsis [10]. Yet it was unclear whether culture data reflected only postmortem or perimortem cultures, or incorporated laboratory results taken earlier during hospitalization a period in which positive cultures would be expected.

\footnotetext{
* Correspondence: leew@smh.ca

${ }^{2}$ Interdepartmental Division of Critical Care, University of Toronto, 30 Bond

Street, Bond Wing 4-012, Toronto, Ontario M5B 1 W8, Canada

${ }^{4}$ Keenan Research Centre for Biomedical Science, St Michael's Hospital, 30

Bond Street, Toronto, Ontario M5B 1 W8, Canada

Full list of author information is available at the end of the article
}

The second study did not report the incidence of positive cultures in patients who died from sepsis, a critical statistic for determining the contribution of nosocomial infection to mortality [1]. This study described three phases of mortality, divided into deaths occurring within hospital days 0 to 5 (phase I), days 6 to 15 (phase II) and days 16 to 150 (phase III). Despite the fact that phase III included the largest number of days by far, the mortality rate was highest in phase I, arguing against late nosocomial infection being the main cause of death.

A recent retrospective analysis in our own center has provided further evidence against this theory. We considered all patients admitted to the ICU who were screened for a sepsis study of heparin (Heparin Anticoagulation to Improve Outcomes in Septic Shock; ClinicalTrials.gov NCT 1648036) and subsequently died. From these patients, we selected those who actually had sepsis and looked for evidence of a secondary nosocomial infection, defined as a detected new microbial isolate prior to death. Of 26 consecutive patients dying of septic shock in a mixed medical-surgical ICU, only three (14\%) patients had evidence of a new infection at the time of death (Table 1). While our study is not definitive, taken together with other results, the theory that nosocomial infection is the predominant cause of death from sepsis seems tenuous.

\section{If not infection, what else? Mitochondrial dysfunction}

There is substantial evidence for mitochondrial dysfunction in sepsis [11]. The theory is that if perfusion and oxygen content are adequate but organ dysfunction still exists, the cells must be unable to use oxygen. Several factors, including reactive oxygen species, hormonal deficiencies, and the impact of systemic inflammation on mitochondrial gene transcription, are thought to contribute [11,12]. Furthermore, leukocytes from septic patients have been shown to possess abnormal oxygen metabolism [13], and mitochondrial dysfunction has been associated with poor outcomes in septic shock [14]. While trials of antioxidant 
Table 1 Lack of evidence of nosocomial infection in a retrospective cohort of patients dying of sepsis

\begin{tabular}{|c|c|c|c|c|c|c|c|c|}
\hline Age range (years) & Source of infection & SOFA score & ICU LOS (days) & $\begin{array}{l}\text { Days from diagnosis } \\
\text { to death }\end{array}$ & $\begin{array}{l}\text { Days from final } \\
\text { culture to death }\end{array}$ & $\begin{array}{l}\text { Final culture } \\
\text { result }\end{array}$ & $\begin{array}{l}\text { Cause of } \\
\text { death }\end{array}$ & $\begin{array}{l}\text { Evidence of nosocomial } \\
\text { infection }\end{array}$ \\
\hline 70 to 79 & Lung & 12 & 16 & 13 & 1 & No growth & Cancer & No nosocomial infection \\
\hline 60 to 69 & Skin and soft tissue & 9 & 55 & 55 & 5 & No growth & $\mathrm{CHF}$ & No nosocomial infection \\
\hline 80 to 89 & Genitourinary & 12 & 1 & 14 & 2 & No growth & $\mathrm{CHF}$ & No nosocomial infection \\
\hline 70 to 79 & Bloodstream & 15 & 17 & 17 & 2 & Original organism & IE/sepsis & No nosocomial infection \\
\hline 80 to 89 & Lung & 18 & 54 & 73 & $<1$ & Original organism & Ischemic bowel & No nosocomial infection \\
\hline 40 to 49 & Intra-abdominal & 12 & 14 & 14 & 14 & No growth & Liver failure & No nosocomial infection \\
\hline 80 to 89 & Lung & 11 & 12 & 10 & 1 & No growth & $\mathrm{Ml}$ & No nosocomial infection \\
\hline 70 to 79 & Lung & 10 & 5 & 3 & 1 & Original organism & $\mathrm{Ml}$ & No nosocomial infection \\
\hline 40 to 49 & Bloodstream & 21 & 14 & 4 & 1 & No growth & MOF & No nosocomial infection \\
\hline 50 to 59 & Bloodstream & 15 & 16 & 33 & 3 & No growth & MOF & No nosocomial infection \\
\hline 40 to 49 & Intra-abdominal & 17 & 4 & 5 & 1 & No growth & MOF & No nosocomial infection \\
\hline 70 to 79 & Intra-abdominal & 16 & 42 & 43 & 3 & No growth & MOF & No nosocomial infection \\
\hline 60 to 69 & Lung & 9 & 19 & 18 & 2 & No growth & MOF & No nosocomial infection \\
\hline 50 to 59 & Skin and soft tissue & 13 & 10 & 11 & 1 & No growth & MOF & No nosocomial infection \\
\hline 60 to 69 & Skin and soft tissue & 14 & 76 & 57 & 2 & No growth & MOF & No nosocomial infection \\
\hline$<30$ & Skin and soft tissue & 14 & 86 & 85 & $<1$ & No growth & MOF & No nosocomial infection \\
\hline 80 to 89 & Genitourinary & 16 & 1 & 1 & 1 & Original organism & MOF & No nosocomial infection \\
\hline 70 to 79 & Lung & 4 & 34 & 22 & 3 & No growth & Tumor lysis & No nosocomial infection \\
\hline 40 to 49 & Intra-abdominal & 7 & 46 & 74 & 1 & New organism & MOF & Nosocomial infection \\
\hline 70 to 79 & Intra-abdominal & 5 & 6 & 6 & 1 & New organism & MOF & Nosocomial infection \\
\hline$<30$ & Intra-abdominal & 12 & 37 & 37 & $<1$ & New organism & Pancreatitis & Nosocomial infection \\
\hline 60 to 69 & Intra-abdominal & 5 & 1 & 7 & 3 & New organism & MOF & Indeterminate \\
\hline 50 to 59 & Skin and soft tissue & 12 & 37 & 37 & 4 & No growth & MOF & Indeterminate \\
\hline 40 to 49 & Lung & 16 & 68 & 50 & 6 & No growth & MOF & Indeterminate \\
\hline 70 to 79 & Lung & 13 & 17 & 17 & 13 & Original organism & MOF & Indeterminate \\
\hline 70 to 79 & Intra-abdominal & 14 & 3 & 13 & $<1$ & No growth & Sepsis & Indeterminate \\
\hline
\end{tabular}

The initial antibiotic therapy was checked against culture and sensitivity results to record the appropriateness of antibiotic therapy for the initial isolate. Results of the final culture before death and the time from that culture until death are indicated ( $<1$ means the same day as death). CHF, congestive heart failure; IE, infective endocarditis; LOS, length of stay; MI, myocardial infarction; MOF, multiorgan failure; SOFA, Sequential 
therapy have been unsuccessful (reviewed in [2]), further trials are needed to determine the validity of this approach.

\section{Microvascular leak}

Another theory for death from sepsis implicates systemic vascular leak (Figure 1) [15,16]. Loss of endothelial barrier integrity leads to tissue edema, hypoperfusion, and organ dysfunction. These features are characteristic of human sepsis but until recently were absent from animal models. Importantly, various lines of evidence for this theory exist. In mice, buttressing the endothelial barrier directly protected against death from sepsis $[17,18]$. In humans, limiting fluids accelerated recovery in acute respiratory distress syndrome [19], while a positive fluid balance was associated with worse outcome in sepsis [20]; most recently, in a post hoc subgroup of the sickest sepsis patients, albumin therapy - which would limit edema formation - was also protective [21].

\section{Conclusion}

Sepsis has been termed a pharmaceutical 'graveyard' [22] due to repeated failure of human clinical trials. Despite calls for a trial of immunoadjuvant therapy, the evidence supporting nosocomial infection as the main cause of death is weak. A small study of granulocyte-macrophage colony-stimulating factor in patients with severe sepsis/

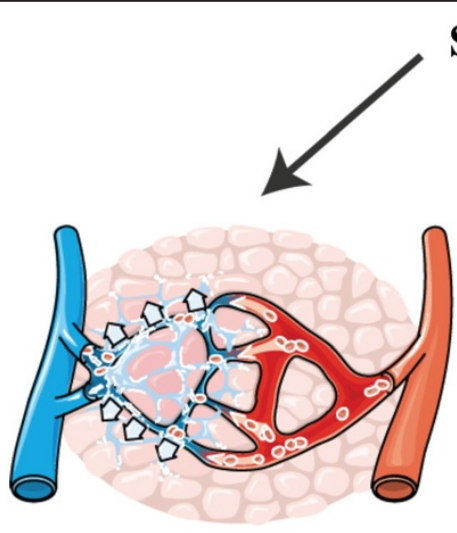

Endothelial barrier disruption
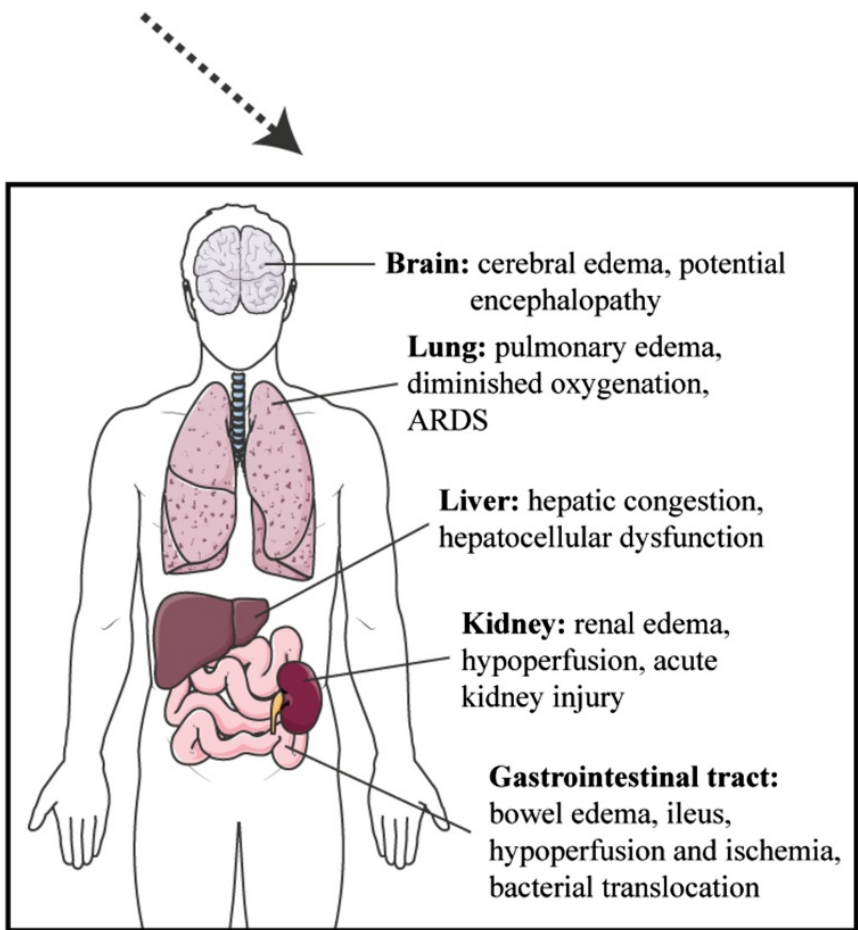

Figure 1 Evidence supporting nosocomial infection as the major cause of death in sepsis is weak. Alternative hypotheses include the role of mitochondrial dysfunction as well as systemic microvascular leak (see text). ARDS, acute respiratory distress syndrome. 
septic shock observed improvements in monocyte function but no significant change in a host of clinical parameters except for the duration of mechanical ventilation [23]. Practically, if most patients who die from sepsis have sterile cultures, it is unlikely that boosting the immune system or adding additional antibiotics will improve outcomes. Further research into the contribution of nosocomial infection to sepsis mortality is thus necessary, as well as research into other potential contributors such as systemic microvascular leak.

\section{Competing interests}

The authors declare that they have no competing interests.

\section{Acknowledgements}

The retrospective chart review was approved by the Research Ethics Board at St Michael's Hospital, Toronto, Ontario, Canada (\#REB 13-273c). The authors would like to thank the Heparin Anticoagulation to Improve Outcomes in Septic Shock research nurses and personnel for their help with this study.

\section{Author details}

${ }^{1}$ Keenan Research Centre for Biomedical Science, St Michael's Hospital, 30 Bond Street, Toronto, Ontario M5B 1 W8, Canada. ${ }^{2}$ Interdepartmental Division of Critical Care, University of Toronto, 30 Bond Street, Bond Wing 4-012, Toronto, Ontario M5B 1 W8, Canada. 'Li Ka Shing Knowledge Institute, St Michael's Hospital, 30 Bond Street, Toronto, Ontario M5B 1 W8, Canada. ${ }^{4}$ Keenan Research Centre for Biomedical Science, St Michael's Hospital, 30 Bond Street, Toronto, Ontario M5B 1 W8, Canada.

\section{Published online: 01 October 2014}

\section{References}

1. Otto GP, Sossdorf M, Claus RA, Rödel J, Menge K, Reinhart K, Bauer M, Riedemann NC: The late phase of sepsis is characterized by an increased microbiological burden and death rate. Crit Care 2011, 15:R183.

2. Riedemann NC, Guo R-F, Ward PA: Novel strategies for the treatment of sepsis. Nat Med 2003, 9:517-524.

3. Hotchkiss RS, Monneret G, Payen D: Immunosuppression in sepsis: a novel understanding of the disorder and a new therapeutic approach. Lancet Infect Dis 2013, 13:260-268.

4. Abraham E, Wunderink $R$, Silverman $H$, Perl TM, Nasraway $S$, Levy $H$, Bone $R$, Wenzel RP, Balk R, Allred R: Efficacy and safety of monoclonal antibody to human tumor necrosis factor alpha in patients with sepsis syndrome. A randomized, controlled, double-blind, multicenter clinical trial. TNF-alpha MAb Sepsis Study Group. JAMA 1995, 273:934-941.

5. Bone RC, Fisher CJ, Clemmer TP, Slotman GJ, Metz CA, Balk RA: A controlled clinical trial of high-dose methylprednisolone in the treatment of severe sepsis and septic shock. N Engl J Med 1987, 317:653-658.

6. Boomer JS, To K, Chang KC, Takasu O, Osborne DF, Walton AH, Bricker TL, Jarman SD, Kreisel D, Krupnick AS, Srivastava A, Swanson PE, Green JM, Hotchkiss RS: Immunosuppression in patients who die of sepsis and multiple organ failure. JAMA 2011, 306:2594-2605.

7. Hotchkiss RS, Monneret G, Payen D: Sepsis-induced immunosuppression: from cellular dysfunctions to immunotherapy. Nat Rev Immunol 2013, 13:862-874

8. Payen D, Monneret G, Hotchkiss R: Immunotherapy - a potential new way forward in the treatment of sepsis. Crit Care 2013, 17:118

9. Unsinger J, Kazama H, McDonough JS, Griffith TS, Hotchkiss RS, Ferguson TA: Sepsis-induced apoptosis leads to active suppression of delayed-type hypersensitivity by CD8+ regulatory T cells through a TRAIL-dependent mechanism. J Immunol 2010, 184:6766-6772.

10. Torgersen C, Moser P, Luckner G, Mayr V, Jochberger S, Hasibeder WR, Dünser MW: Macroscopic postmortem findings in 235 surgical intensive care patients with sepsis. Anesth Analg 2009, 108:1841-1847.

11. Singer $M$ : The role of mitochondrial dysfunction in sepsis-induced multi-organ failure. Virulence 2014, 5:66-72.
12. Singer M: Powering up failed organs. Am J Respir Crit Care Med 2007, 176:733-734.

13. Belikova I, Lukaszewicz AC, Faivre V, Damoisel C, Singer M, Payen D: Oxygen consumption of human peripheral blood mononuclear cells in severe human sepsis. Crit Care Med 2007, 35:2702-2708.

14. Brealey D, Brand M, Hargreaves I, Heales S, Land J, Smolenski R, Davies NA, Cooper CE, Singer M: Association between mitochondrial dysfunction and severity and outcome of septic shock. The Lancet 2002, 360:219-223.

15. Lee WL, Slutsky AS: Sepsis and endothelial permeability. N Engl J Med 2010, 363:689-691.

16. Goldenberg NM, Steinberg BE, Slutsky AS, Lee WL: Broken barriers: a new take on sepsis pathogenesis. Sci Trans/ Med 2011, 3:88ps25.

17. London NR, Zhu W, Bozza FA, Smith MCP, Greif DM, Sorensen LK, Chen L, Kaminoh Y, Chan AC, Passi SF, Day CW, Barnard DL, Zimmerman GA, Krasnow MA, Li DY: Targeting Robo4-dependent Slit signaling to survive the cytokine storm in sepsis and influenza. Sci Trans/ Med 2010, 2:23ra19.

18. Kümpers P, Gueler F, David S, Slyke PV, Dumont DJ, Park J-K, Bockmeyer CL, Parikh SM, Pavenstadt H, Haller H, Shushakova N: The synthetic tie2 agonist peptide vasculotide protects against vascular leakage and reduces mortality in murine abdominal sepsis. Crit Care 2011, 15:R261.

19. Heart N, Lung, and Blood Institute Acute Respiratory Distress Syndrome (ARDS) Clinical Trials Network, Wiedemann HP, Wheeler AP, Bernard GR, Thompson BT, Hayden D, DeBoisblanc B, Connors AF, Hite RD, Harabin AL: Comparison of two fluid-management strategies in acute lung injury. $N$ Engl J Med 2006, 354:2564-2575.

20. Boyd JH, Forbes J, Nakada T-A, Walley KR, Russell JA: Fluid resuscitation in septic shock: a positive fluid balance and elevated central venous pressure are associated with increased mortality. Crit Care Med 2011, 39:259-265

21. Caironi P, Tognoni G, Masson S, Fumagalli R, Pesenti A, Romero M, Fanizza C, Caspani L, Faenza S, Grasselli G, lapichino G, Antonelli M, Parrini V, Fiore G, Latini R, Gattinoni L, ALBIOS Study Investigators: Albumin replacement in patients with severe sepsis or septic shock. N Engl J Med 2014, 371:84.

22. Riedemann NC, Guo R-F, Ward PA: The enigma of sepsis. J Clin Invest 2003, 112:460-467.

23. Meisel C, Schefold JC, Pschowski R, Baumann T, Hetzger K, Gregor J, Weber-Carstens S, Hasper D, Keh D, Zuckermann H, Reinke P, Volk H-D: Granulocyte-macrophage colony-stimulating factor to reverse sepsis-associated immunosuppression: a double-blind, randomized, placebo-controlled multicenter trial. Am J Respir Crit Care Med 2009, 180:640-648.

doi:10.1186/s13054-014-0540-y

Cite this article as: Goldenberg et al:: Is nosocomial infection really the major cause of death in sepsis?. Critical Care 2014 18:540. 